\title{
Antioxidant Action and In Vivo Anti-Inflammatory and Antinociceptive Activities of Myrciaria floribunda Fruit Peels: Possible Involvement of Opioidergic System
}

\author{
Izabelly Bianca da Silva Santos, ${ }^{1}$ Bruno Santos dos Santos, ${ }^{1}$ \\ João Ricardhis Saturnino de Oliveira, ${ }^{1}$ Wêndeo Kennedy Costa, ${ }^{1}$ Adrielle Zagmignan, \\ Luís Cláudio Nascimento da Silva $\mathbb{D}^{2},{ }^{2}$ Magda Rhayanny Assunção Ferreira $\mathbb{D}^{3}{ }^{3}$ \\ Vilmar Luiz Lermen, ${ }^{4}$ Maria Silvanete Benedito de Sousa Lermen, ${ }^{4}$ \\ Alexandre Gomes da Silva, ${ }^{1}$ Rafael Matos Ximenes, ${ }^{5}$ Luiz Alberto Lira Soares, ${ }^{3}$ \\ Patrícia Maria Guedes Paiva $\mathbb{D D}^{1},{ }^{1}$ Vera Lúcia de Menezes Lima $\mathbb{D D}^{1}{ }^{1}$ \\ Maria Tereza dos Santos Correia $\left(\mathbb{D},{ }^{1}\right.$ and Márcia Vanusa da Silva ${ }^{1}{ }^{1}$ \\ ${ }^{1}$ Departamento de Bioquímica, Universidade Federal de Pernambuco, Recife, PE 50670-901, Brazil \\ ${ }^{2}$ Programa de Pós-Graduação, Universidade Ceuma, São Luís, MA 65075-120, Brazil \\ ${ }^{3}$ Departamento de Ciências Farmacêuticas, Universidade Federal de Pernambuco, Recife, PE 50670-901, Brazil \\ ${ }^{4}$ Comunidade Serra dos Paus Dóias Chapada do Araripe, Exu, PE 56230-000, Brazil \\ ${ }^{5}$ Departamento de Antibióticos, Universidade Federal de Pernambuco, Recife, PE 50670-901, Brazil
}

Correspondence should be addressed to Márcia Vanusa da Silva; marciavanusa@yahoo.com.br

Received 16 November 2019; Revised 21 February 2020; Accepted 13 March 2020; Published 27 April 2020

Academic Editor: Srinivas Mutalik

Copyright (c) 2020 Izabelly Bianca da Silva Santos et al. This is an open access article distributed under the Creative Commons Attribution License, which permits unrestricted use, distribution, and reproduction in any medium, provided the original work is properly cited.

\begin{abstract}
This work evaluated the antioxidant properties and in vivo antinociceptive and anti-inflammatory effects of extracts obtained from fruit peels of Myrciaria floribunda (H. West ex Willd.) O. Berg (Myrtaceae). This plant is popularly known in Brazil as Cambuí or camboim. Different extracts were submitted to comparative analysis to determine the content of selected phytochemical classes (levels of total phenols, flavonoids, and monomeric anthocyanins) and the in vitro antioxidant potentials. The extract with higher potential was selected for in vivo evaluation of its antinociceptive and anti-inflammatory action. Finally, the chemical characterization of this extract was performed by high-performance liquid chromatography (HPLC). MfAE (extract obtained using acetone as solvent) showed the higher levels of phenols (296 mg GAE/g) and anthocyanins contents (35.65 mg Cy-3-glcE/g) that were associated with higher antioxidant activity. MfAE also exhibited in vivo anti-inflammatory and analgesic propertiers. This fraction inhibited the inflammatory and neurogenic phases of pain, and this effect was reversed by naloxone (suggesting the involvement of opioidergic system). MfAE reduced the abdominal contortions induced by acetic acid. The HPLC analysis revealed the presence of gallic acid (and its derivatives) and ellagic acid. Taken together, these data support the use of $M$. floribunda fruit peels for development of functional foods and nutraceutics.
\end{abstract}

\section{Introduction}

Free radicals (and associated reactive species) are in general derived from normal metabolism and are crucial for redox signaling pathways and immune defense [1-4]. However, these molecules can interact with cellular structures leading to impairment of physiological systems [5-7]. In this sense, the oxidative stress has been associated with the etiology of several pathologies such as inflammatory disorders, chronic pain, and degenerative diseases [8-10].

Inflammation is a complex condition triggered by several stimuli (mechanical injuries, toxic compounds, tissue 
ischemia, and infectious agents) and marked by tissue alteration that allows the intense migration of immune cells to the inflammatory focus [11-13]. Usually, the release of proinflammatory substances (cytokines, nitric oxide, and other reactive species) is reduced after the eradication of stimuli, leading to the resolution phase $[13,14]$. However, in some situations, the resolution of inflammation is not achieved, resulting in excessive or inappropriate inflammation [11]. This condition is associated with several diseases such as cancer, diabetes, rheumatoid arthritis, and psoriasis $[12,15]$. In this case, the high levels of reactive species lead to tissue damage and organ dysfunction $[2,4,5]$.

The excessive release of inflammatory mediators can result in the establishment of inflammatory pain $[16,17]$. For example, the cytokines TNF- $\alpha$, IL- $1 \beta$, and IL- 6 (produced by macrophages and other immune cells) interact with nociceptive neurons and modulated central sensitization, pain, and hyperalgesia [18-20]. Furthermore, other substances produced by immune cells, such as histamines and prostaglandins, also play important roles in pain regulation $[17,21,22]$. In this context, pain and inflammation have a tightly regulated relationship, since the nociceptive neurons also regulate the inflammatory response [17, 21, 23].

Despite the number of anti-inflammatory and analgesic drugs available in the market, the treatment schedules of these clinical conditions are complex and pose huge challenges to the health systems worldwide [24, 25]. This scenario points out the urgent need for the development of effective analgesic and anti-inflammatory drugs [26-28].

Several scientific evidences report that fruits are valuable sources of compounds with antioxidant properties, and their consumption may be beneficial to reduce the deleterious effects of inflammatory disorders and chronic pain [29-32]. In this sense, there is a growing interest in knowing the anti-inflammatory and analgesic properties of edible fruits (and their different parts) in order to provide more insights into supporting their use as functional foods and nutraceuticals [30, 33, 34].

Myrciaria floribunda ( $\mathrm{H}$. West ex Willd.) O. Berg (Myrtaceae) is native plant of South and Central America, which is distributed in different Brazilian biomes such as Amazon, Caatinga, Cerrado, and Atlantic Forest. Its fruits (known in Brazil as Cambuí or camboim) are edible and often consumed freshly, in juices or alcoholic beverages [35]. Some works have shown the pharmacological properties of different parts of this plant such as antioxidant, antimicrobial, and anticancer effects [36, 37]. However, the pharmacological actions of the fruits were not properly addressed [35]. In particular, the beneficial aspects of the products derived from fruit peels of the $M$. floribunda have not been demonstrated. This work analyzed the phytochemical composition along with the antioxidant, antinociceptive, and anti-inflammatory potentials of extracts obtained from fruit peels of $M$. floribunda.

\section{Materials and Methods}

2.1. Plant Material. Fruits of $M$. floribunda were collected from Serra dos Paus Dóias (Exu, Pernambuco, Brazil) in 2015. The plant material was identified by Alexandre Gomes da Silva (Department of Antibiotics, Federal University of Pernambuco, Brazil). The specimen voucher (number: 92722) was deposited in the Herbarium of the Agronomic Institute of Pernambuco.

2.2. Plant Extracts. The fruits were washed with running water and manually separated into pulp, seed, and peel. Samples of the fruit peels were dried at $40^{\circ} \mathrm{C}$ and reduced to fine powder. The fruit peel powder $(50 \mathrm{~g})$ was extracted with $500 \mathrm{~mL}$ of ethyl ether $(1: 10, \mathrm{w} / \mathrm{v})$ in brown glass bottles with cap by vigorous shaking for 1 hour at room temperature $\left(30^{\circ} \mathrm{C}\right)$. The extract was then filtered, and the residue was re-extracted twice more following the same procedure with $500 \mathrm{~mL}$. After this process, the residue was extracted with other solvents (in the sequence chloroform, acetone, and methanol), and all extraction steps were repeated as described above. At each step, the obtained extracts were dried in a rotaevaporator at $40^{\circ} \mathrm{C}$, generating extracts MfEeE (ethyl ether), MfCE (chloroform), MfAE (acetone), and MfME (methanol). Aqueous extraction was also performed with $10 \mathrm{~g}$ of the powder with $100 \mathrm{~mL}$ of distilled water $(1: 10, \mathrm{w} / \mathrm{v})$; then, the solution was filtered and lyophilized, generating the extract MfAqE.

2.3. Phytochemical Analysis. The presence of several kinds of phytochemicals (flavonoids, phenylpropanoids, triterpenes, steroids, saponins, monoterpenes, sesquiterpenes, coumarins, quinones, alkaloids, proanthocyanidins, and water-soluble tannins) was investigated in each extract using thin-layer chromatography with silica gel plate $F_{254}\left(A L U G R A M^{R}\right.$ 818131, Macherey-Nagel, Germany), and for each elution system, specific visualization agents and standards were used to identify the metabolites as described in Table 1 [38-41].

\subsection{Total Phenol Content, Total Flavonoid, and Monomeric} Anthocyanins. The levels of total phenols were estimated using the Folin-Ciocalteu method [42], with some modifications. Samples of $20 \mu \mathrm{L}$ of each extract $(1 \mathrm{mg} / \mathrm{mL})$ were mixed with $100 \mu \mathrm{L}$ of the Folin-Ciocalteu reagent. After 3 minutes at room temperature, $80 \mu \mathrm{L}$ of a sodium bicarbonate solution $(0.7 \mathrm{M})$ was added. The reaction was kept in the dark for 2 hour at room temperature. The absorbance was measured at $735 \mathrm{~nm}$ using a microplate reader (BioTek uQuant MQX200). Methanol and distilled water were used as negative controls. Gallic acid was used as standard, and the results were calculated based on the calibration curve of gallic acid (10-100 $\mu \mathrm{g} / \mathrm{mL})$ and expressed as mg equivalent of gallic acid per gram of extract (GAE/g extract).

The flavonoid content was determined according to the colorimetric method of aluminum chloride [43]. The extracts were tested at the concentration of $1 \mathrm{mg} / \mathrm{mL}$, and quercetin was used to obtain the standard calibration curve $(10-100 \mu \mathrm{g} / \mathrm{mL})$. The sample $(100 \mu \mathrm{L})$ was mixed with $100 \mu \mathrm{L}$ of the reagent [ $2 \%$ aluminum chloride $\left(\mathrm{AlCl}_{3}\right)$ in methanol]; after 1 hour in dark-room-temperature environment, absorbance was read against a blank of methanol or more distilled water, the reagent, at $420 \mathrm{~nm}$. The results obtained were expressed as $\mathrm{mg}$ equivalent of quercetin per gram of 
TABLE 1: Elution systems, chromogenic agents, and standards used in the phytochemical analysis of extracts from fruit peels of Myrciaria floribunda with thin-layer chromatography (TLC).

\begin{tabular}{|c|c|c|c|}
\hline Secondary metabolite classes & Standard & Mobile phase & Chromogenic agent \\
\hline $\begin{array}{l}\text { Flavonoids and } \\
\text { phenylpropanoids }\end{array}$ & $\begin{array}{l}\text { Quercetin, rutin, and } \\
\text { chlorogenic acid }\end{array}$ & $\begin{array}{l}\text { EtOAc-HCOOH-AcOH-H}{ }_{2} \mathrm{O}(100: \\
11: 11: 26 \mathrm{v} / \mathrm{v})\end{array}$ & $\begin{array}{l}\text { Natural products-polyethylene } \\
\text { glycol reagent }\end{array}$ \\
\hline Triterpenes and steroids & $\beta$-Sitosterol & Toluene:EtOAc $(90: 10 \mathrm{v} / \mathrm{v})$ & Liebermann-Burchard reagent \\
\hline Saponins & Escin & $\begin{array}{l}\text { EtOAc-HCOOH-AcOH-H }{ }_{2} \mathrm{O}(100: \\
11: 11: 26 \mathrm{v} / \mathrm{v})\end{array}$ & Liebermann-Burchard reagent \\
\hline Mono and sesquiterpenes & Thymol & Toluene:EtOAc $(97: 3 \mathrm{v} / \mathrm{v})$ & $\begin{array}{c}\text { Anisaldehyde-sulfuric acid } \\
\text { reagent }\end{array}$ \\
\hline Coumarins and quinones & Coumarin and lapachol & $\mathrm{CHCl}_{3}-\mathrm{MeOH}(98: 2 \mathrm{v} / \mathrm{v})$ & Potassium hydroxide reagent \\
\hline Alkaloids & Pilocarpine & $\begin{array}{c}\text { EtOAc-HCOOH-AcOH-H}{ }_{2} \mathrm{O}(100: \\
11: 11: 26 \mathrm{v} / \mathrm{v})\end{array}$ & Dragendorff reagent \\
\hline Proanthocyanidins & Catechin & $\begin{array}{c}\text { EtOAc-HCOOH-AcOH-H}{ }_{2} \mathrm{O}(100: \\
11: 11: 26 \mathrm{v} / \mathrm{v})\end{array}$ & $\begin{array}{c}\text { Vanillin-hydrochloric acid } \\
\text { reagent }\end{array}$ \\
\hline Hydrolysable tannins & Gallic acid & $n$ - $\mathrm{BuOH}-\mathrm{H}_{2} \mathrm{O}-\mathrm{AcOH}(40: 50: 10 \mathrm{v} / \mathrm{v})$ & Ferric ammonium sulfate $1 \%$ \\
\hline
\end{tabular}

extract (mg QE/g extract). The experiment was done in triplicate.

The content of monomeric anthocyanins was determined by the differential $\mathrm{pH}$ method [44]. Potassium chloride buffer (KCl; $0.025 \mathrm{M} ; \mathrm{pH} 1)$ and sodium acetate buffer $\left(\mathrm{CH}_{3} \mathrm{CO}_{2} \mathrm{Na} ; 0.4 \mathrm{M} ; \mathrm{pH} 4.5\right)$ were used. The sample $(200 \mu \mathrm{L}$ at $10 \mathrm{mg} / \mathrm{mL})$ was mixed to $1.8 \mathrm{~mL}$ of each buffer. After 10 minutes, the absorbance was read at $520 \mathrm{~nm}$ and at $700 \mathrm{~nm}$. The distilled water was used as control. The concentration of anthocyanin was calculated according to the following equation, and the results were expressed as cyanidin-3-glucoside equivalent (Cy-3-glcE):

$$
\text { anthocyanin content }=\frac{\left(A \times \mathrm{MW} \times \mathrm{DF} \times 10^{3}\right)}{\varepsilon \times 1} .
$$

$A=($ absorbance $520 \mathrm{~nm}-$ absorbance $700 \mathrm{~nm})$ at $\mathrm{pH} 1$ -(absorbance $520 \mathrm{~nm}$-absorbance $700 \mathrm{~nm}$ ) at $\mathrm{pH} 4.5$; MW $($ molecular weight $)=449.2 \mathrm{~g} / \mathrm{mol}$ of $\mathrm{Cy}-3-\mathrm{glc} ; \mathrm{DF}=$ dilution factor $(0.2 \mathrm{~mL}$ of the sample was diluted to $2 \mathrm{~mL}, \mathrm{DF}=10)$; $1=$ length in $\mathrm{cm} ; \varepsilon=26900$, molar extinction coefficient, in $\mathrm{L}$ $\mathrm{x} \mathrm{mol}{ }^{-1} \mathrm{x} \mathrm{cm}^{-1}$, for Cy-3-glc; and $10^{3}=$ factor for conversion from $\mathrm{g}$ to $\mathrm{mg}$.

\subsection{Antioxidant Assays}

2.5.1. DPPH Assay (Free Radical Sequestration). For evaluation of the ability to sequester the DPPH (2,2-diphenyl-1picryl-hydrazyl) radical, an aliquot of $40 \mu \mathrm{L}$ of each extract at different concentrations $(8.0625$ to $1000 \mu \mathrm{g} / \mathrm{mL})$ was mixed with $250 \mu \mathrm{L}$ of $1 \mathrm{mM} \mathrm{DPPH}$ solution (in methanol) for 25 minutes at room temperature and protected from light [45]. Gallic acid was the standard used as a positive control, and methanol was the negative control. A control solution $(40 \mu \mathrm{L}$ of the extract and $250 \mu \mathrm{L}$ of the solvent used to dilute the samples) was used to rule out the possible interference of extract color. The absorbance of each solution was measured at $517 \mathrm{~nm}$ using a microplate reader (BioTek uQuant MQX200).
2.5.2. ABTS Assay. The ABTS (2,2-azino-bis (3-ethylbenzothiazoline-6-sulfonic acid)) radical was obtained by mixing $5 \mathrm{~mL}$ of the ABTS stock solution $(7 \mathrm{mM})$ with $88 \mu \mathrm{L}$ of $140 \mathrm{mM}$ potassium persulfate solution. This mixture remained in the dark and at room temperature for 16 hours before use. The ABTS radical solution was diluted with ethanol until an absorbance of $0.7 \mathrm{~nm}( \pm 0.02)$ was obtained at $734 \mathrm{~nm}$. Samples $(10 \mu \mathrm{L})$ of the extracts $(1 \mathrm{mg} / \mathrm{mL})$ were mixed with $1 \mathrm{~mL}$ of the ABTS radical for 6 minutes and then read off a spectrophotometer at $734 \mathrm{~nm} \mathrm{[46].} \mathrm{Trolox} \mathrm{was}$ used as standard antioxidant $(100 \mu \mathrm{M}$ to $2000 \mu \mathrm{M})$. The result was expressed as Trolox equivalent antioxidant capacity (TEAC) in $\mu \mathrm{M}$ TE/g extract.

2.5.3. Total Antioxidant Capacity (TAC). Samples $(100 \mu \mathrm{L})$ of the extracts $(1 \mathrm{mg} / \mathrm{mL})$ were combined with $1 \mathrm{~mL}$ of the reagent solution $(0.6 \mathrm{M}$ sulfuric acid, $28 \mathrm{mM}$ sodium phosphate, and $4 \mathrm{mM}$ ammonium molybdate). The tubes were incubated at $95^{\circ} \mathrm{C}$ for 90 minutes and then cooled to room temperature, and the absorbance of each reaction was read at $695 \mathrm{~nm}$. The control reaction consisted in $100 \mu \mathrm{L}$ of methanol mixed with $1 \mathrm{~mL}$ of the reagent solution [47]. The standard used was ascorbic acid $(1 \mathrm{mg} / \mathrm{mL})$. The result was calculated according to the formula below and was expressed as total antioxidant capacity (TAC) relative to ascorbic acid.

$$
\mathrm{TAC} \%=\frac{S_{\mathrm{abs}}-B_{\mathrm{abs}}}{\mathrm{AA}_{\mathrm{abs}}-B_{\mathrm{abs}}} * 100,
$$

where $S_{\mathrm{abs}}$ is the absorbance of the sample (extracts), $B_{\mathrm{abs}}$ is the absorbance of control, and $\mathrm{AA}_{\mathrm{abs}}$ is the absorbance of ascorbic acid.

2.5.4. Determination of the Sequestration of the Superoxide Radical. In this assay, the reaction mixture consisted of $300 \mu \mathrm{L}$ of extracts at different concentrations $(50-1000 \mu \mathrm{g} / \mathrm{mL})$, $100 \mu \mathrm{L}$ of NBT (nitrotetrazolium blue chloride) $(1 \mathrm{mg} / \mathrm{mL}$ in DMSO solution), and $1 \mathrm{~mL}$ of alkaline DMSO (1 mL DMSO 
containing $5 \mathrm{mM}$ sodium hydroxide in $0.1 \mathrm{~mL}$ water), and the absorbance was measured at $560 \mathrm{~nm}$ [48].

2.6. HPLC Analysis. For high-performance liquid chromatography (HPLC) analysis, $20 \mathrm{mg}$ of the MfAE was weighed and diluted with methanol $50 \%(\mathrm{v} / \mathrm{v})$ to a volumetric flask of $2 \mathrm{~mL}$ and filtered through a $0.45 \mu \mathrm{m}$ PVDF membrane (Macherey-Nagel ${ }^{\circledR}$ ) for sample injection. The system was the Ultimate 3000 (Thermo Fisher Scientific ${ }^{\circledR}$, EUA) coupled to a photodiode array detector (DAD; Thermo Fisher Scientific $^{\circledR}$ ) and equipped with a binary pump (HPG-3x00RS; Thermo Fisher Scientific $\left.{ }^{\circledR}\right)$, degasser, and automatic sampler loop volume of $20 \mu \mathrm{L}$ (ACC-3000; Thermo Fisher Scientific). The wavelength for the analyses was set at $270 \mathrm{~nm}$.

The chromatographic separation was performed at $26^{\circ} \mathrm{C}$ using a column Dionex ${ }^{\circledR} \mathrm{C}_{18}(250 \mathrm{~mm} \times 4.6 \mathrm{~mm}$ d.i., $5 \mu \mathrm{m})$ equipped with precolumn Phenomenex ${ }^{\circledR}\left(\mathrm{C}_{18} ; 4 \mathrm{~mm} \times 3.9 \mu \mathrm{m}\right)$. The mobile phase consisted of solvent A (purified water, Purelab Classic UV, Elga ${ }^{\circledR}$ ) and solvent B (methanol, HPLC grade, Tedia $^{\circledR}$ ), both acidified with $0.05 \%$ trifluoracetic acid (Vetec ${ }^{\circledR}$ ), and the flow rate was adjusted to $0.9 \mathrm{~mL} /$ minute. The following gradient program was used: $0-10$ minutes, $10-20 \%$ of solvent $\mathrm{B}$; $10-13.5$ minutes, $20-25 \%$ of solvent $B ; 13.5-18$ minutes, $25-40 \%$ of solvent B; $18-25$ minutes, $40-80 \%$ of solvent $B ; 25-30$ minutes, $80 \%$ of solvent B; and $30-35$ minutes, $80-10 \%$ of solvent B. The content of the substances found in MfAE was determined from the calibration curves using gallic acid ( $96 \%$ of purity) or ellagic acid (95\% of purity), both purchased from Sigma (USA).

2.7. Ethical Statement. All procedures using animals were approved by the Ethics Committee on the Use of Animals of the Federal University of Pernambuco, Brazil (CEUA-UFPE; Process Number: 0003/2018). The proposal was approved in the meeting of CEUA-UFPE held in April 23, 2018.

2.8. Animals. The experiments were conducted using male Swiss mice (30-35 g, 10 weeks) supplied by the Laboratory of Immunopathology Keizo Asami (LIKA). The animals received food and water standard ad libitum with light/dark period of $12 \mathrm{~h}$. Before each experiment (6-8 hours), animals were limited to a water-only diet to avoid foodborne interference with substance absorption.

2.9. Evaluation of Acute Toxicity. Acute toxicity of MfAE was performed according to the instructions of the Organization for Economic Cooperation and Development (2001). The acute toxicity of MfAE was analyzed in two steps. Phase 1: animals were divided into three groups $(n=3)$ that received MfAE at doses of $10 \mathrm{mg} / \mathrm{kg}, 100 \mathrm{mg} / \mathrm{kg}$, and $1000 \mathrm{mg} / \mathrm{kg}$. The animals are placed under observation for 24 hours to monitor their behavior and survival. Phase 2: MfAE was administered at higher doses $(1600,2900$, and $5000 \mathrm{mg} / \mathrm{kg}$; one mice per dose), and then the behavior and survival were observed for 24 hours [49]. The LD50 was calculated by the following equation:

$$
\mathrm{LD}_{50}=\sqrt{\left(D_{0} \times D_{100}\right)},
$$

$D_{0}=$ highest dose that did not induce mortality and $D_{100}=$ lowest dose that resulted in mice mortality.

2.10. Anti-Inflammatory Assay. The in vivo anti-inflammatory action of MfAE was evaluated by carrageenan-induced paw edema. For this, mice were allocated into four groups $(n=6)$ that received the following treatments: (i) MfAE at $50 \mathrm{mg} / \mathrm{kg}$ (p.o.), (ii) MfAE at $100 \mathrm{mg} / \mathrm{kg}$ (p.o.), (iii) vehicle ( $0.9 \%$ saline solution) (p.o.), or (iv) indomethacin at $20 \mathrm{mg} / \mathrm{kg}$ (p.o.). After $1 \mathrm{~h}$, paw edema was induced by an injection of $2 \%$ carrageenan solution $(15 \mu \mathrm{L} /$ animal $)$ into the subplantar region of the right hind paw [50]. As control, saline solution $(0.9 \% ; 15 \mu \mathrm{L})$ was injected into the left hind paw. Paw volume was measured using digital Vernier caliper at each hour for 5 hours [51]. Inhibition of edema was calculated by evaluating the difference between the volumes of right and left paws.

\subsection{Antinociceptive Assays}

2.11.1. Abdominal Pain Induced by Acetic Acid. The mice were divided into four groups $(n=6)$ and were treated as described above. The nociception was induced by an intraperitoneal injection of acetic acid $(0.8 \% ; 100 \mathrm{~mL} / 10 \mathrm{~g})$. Starting 5 minutes after acetic acid injection, the number of abdominal contortions was recorded for 10 minutes by the number of stretching movements [52].

2.11.2. Formalin Assay. In this assay, the animals were divided into five groups ( $n=6 /$ group) that received the following treatments: (i) vehicle, (ii) MfAE at $50 \mathrm{mg} / \mathrm{kg}$ (p.o.), (iii) MfAE at $100 \mathrm{mg} / \mathrm{kg}$ (p.o.), (iv) indomethacin at $20 \mathrm{mg} / \mathrm{kg}$ (i.p.), and (v) morphine at $10 \mathrm{mg} / \mathrm{kg}$ (p.o.). After $1 \mathrm{~h}$, the formalin solution $(2.5 \%$ in $0.9 \%$ saline; $20 \mu \mathrm{L} /$ paw $)$ was administered into subplantar area of the right hind paw [53]. Mice were observed in a chamber with a mirror mounted onto three sides to allow the observation of the paws. The time (in seconds) spent for licking and biting the injected paw was measured as an indicator of pain. This response was measured for 5 minutes (first phase, neurogenic pain) and between 15 and 30 minutes after formalin injection (second phase, inflammatory pain).

To evaluate the possible involvement of the opioid system in the antinociceptive effect of MfAE, the mice were treated with naloxone $(1 \mathrm{mg} / \mathrm{kg}$, i.p.) 30 minutes prior to administration of MfAE $(100 \mathrm{mg} / \mathrm{kg}$, p.o. $)$ and morphine (10 mg/kg, p.o.).

2.12. Statistical Analysis. The in vitro assays were performed in triplicate in at least two independent assays. The results were expressed as mean ( \pm standard error). The difference between means was tested for statistical significance using one-way or two-way analysis of variance (ANOVA) followed by Tukey's test for multiple comparisons. The $\mathrm{IC}_{50}$ (concentration that inhibits 50\%) was calculated by linear 
regression. In the statistical analysis of the results, the value of $p<0.05$ was considered statistically significant.

\section{Results and Discussion}

3.1. Phytochemical Analysis. The yield of each extract was $8.50 \%, 6.60 \%, 2.05 \%, 5.17 \%$, and $49.27 \%$ for MfAqE, MfEeE, MfCE, MfAE, and MfME, respectively. The chromatographic profile of the extracts from $M$. floribunda fruit peels revealed the presence of several classes of secondary metabolites (Table 2). In the MfEeE and MfCE, monoterpenes, triterpenes, sesquiterpenes, and steroids were found. MfAE is composed by flavonoids, phenylpropanoids, traces of triterpenes and steroids, saponins, and hydrolysable tannins. On the other hand, MfME and MfAqE have flavonoids, polymeric proanthocyanidins, and traces of hydrolysable tannins.

Some classes of secondary metabolites detected in the extracts from fruit peels of $M$. floribunda have been already described for the genus Myrciaria, such as steroids, proanthocyanidins, flavonoids, and hydrolysable tannins $[36,37,54]$. In addition, the edible parts of the M. floribunda fruits are composed by carotenoids (lutein, zeaxanthin, $\beta$-cryptoxanthin, 13 -cis- $\beta$-carotene, $\alpha$-carotene, $\beta$-carotene, and 9 -cis- $\beta$-carotene), flavonoids (rutin), and phenolic acids (gallic acid and ellagic acid) [35].

3.2. Comparative Analysis of the Concentration of Total Phenols, Flavonoids, and Monomeric Anthocyanins. In order to select the extract with the highest potential, we performed a comparative evaluation of the amount of phenols, flavonoids, and monomeric anthocyanins. The content of total phenols varied among the extracts from $7.54 \mathrm{mg} \mathrm{GAE} / \mathrm{g}$ to $296.27 \mathrm{mg} \mathrm{GAE} / \mathrm{g}$ (Table 3). The highest phenol content was obtained for MfAE (296.27 mg GAE/g) (Table 3).

The levels of total flavonoid content ranged from $0.74 \mathrm{mg}$ QE/g to $16.62 \mathrm{mg} \mathrm{QE} / \mathrm{g}$ (Table 3). The MfEeE showed the highest concentration $(16.62 \mathrm{mg} \mathrm{QE} / \mathrm{g})$. Finally, the content of monomeric anthocyanins ranged from $4.34 \mathrm{mg} \mathrm{Cy}-3-$ $\mathrm{glcE} / \mathrm{g}$ to $35.65 \mathrm{mg} \mathrm{Cy}-3-\mathrm{glcE} / \mathrm{g}$ (Table 3) and MfAE showed the highest content (35.65 Cy-3-glcE/g). In summary, MfAE showed the highest content of phenolic compounds and anthocyanins. These classes of compounds have been associated with several beneficial properties of foods and medicinal plants [55-57].

3.3. Comparative Evaluation of Antioxidant Activity. Following, four antioxidant assays were employed to select the extract with the best potential (Table 4). In the DPPH assay, the lower $\mathrm{IC}_{50}$ value was found for $\operatorname{MfAE}(63.84 \mu \mathrm{g} / \mathrm{mL})$, followed by MfME (343.12 $\mu \mathrm{g} / \mathrm{mL}$ ), MfAqE (350.41 v), and MfEeE $(854.94 \mu \mathrm{g} / \mathrm{mL})$. Similarly, MfAE showed the highest ability to inhibit the ABTS radical $(1630.11 \mu \mathrm{M} \mathrm{TEAC/g})$ and total antioxidant capacity (123.91\%). Finally, only MfAE and MfME were able to sequester the superoxide radical, with $\mathrm{IC}_{50}$ values of $260.27 \mu \mathrm{g} / \mathrm{mL}$ and $446.31 \mu \mathrm{g} / \mathrm{mL}$, respectively (Table 4).
The highest antioxidant action exhibited by MfAE may be explained by its higher content of anthocyanins and phenolic compounds, since the levels of these phytocompounds showed positive correlations with the results obtained in the in vitro antioxidants assays (Table 4). In addition, MfAE presented a phytochemical profile with different classes of secondary metabolites, such as flavonoids, phenylpropanoids, triterpenes, saponins, and hydrolysable tannins. Taken together, the results suggest that MfAE is the most promising extract, leading us to select it for the in vivo anti-inflammatory and antinociceptive evaluation.

3.4. HPLC Analysis of the Acetone Extract of M. floribunda. The chromatographic profile of the acetone extract from peels of the fruit (MfAE) is shown in Figure 1. The analysis revealed the presence of gallic acid (peak 1, with retention time of 7.56 minutes) and an indicative presence of ellagic acid (peak 7, with retention time 25.52 minutes). The other peaks (2 to 6) are gallic acid derivatives. The contents of the compounds were calculated as follows: $0.29 \pm 0.0012 \mathrm{~g} \%$ gallic acid, $0.33 \pm 0.0204 \mathrm{~g} \%$ gallic acid (derivatives, peaks of 2 to 6 ), and $0.54 \pm 0.0012 \mathrm{~g} \%$ ellagic acid. The evidenced peaks(gallic acid and ellagic acid) were identified by comparing the retention times and UV spectra of standards. Also, they were confirmed by spiking the sample with a small amount of the standards solutions. Both gallic acid and ellagic acid were previously detected in the fruit of M. floribunda [35].

Gallic acid and ellagic acid (and their derivatives) are usually found in fruits and other plant-derived products $[55,58]$ with antioxidant activity, including those from Myrciaria genus [59, 60]. Furthermore, some works have reported that these compounds are potent anti-inflammatory, analgesic, and neuroprotective agents [60-62].

3.5. Acute Toxicity. The oral lethal dose $\left(\mathrm{LD}_{50}\right)$ of acetone extract was greater than $2000 \mathrm{mg} / \mathrm{kg}\left(\mathrm{LD}_{50}=2154.06 \mathrm{mg} / \mathrm{kg}\right)$, therefore, it can be classified as a low toxic agent according to the Organization for Economic Cooperation and Development [63]. Thus, the doses of $50 \mathrm{mg} / \mathrm{kg}$ and $100 \mathrm{mg} / \mathrm{kg}$ were selected to be applied in the in vivo assays.

3.6. Anti-Inflammatory Activity. The in vivo anti-inflammatory of MfAE was evaluated in a model where the formation of edema was induced by carrageenan. The animals treated with both doses of MfAE demonstrated significant reductions of paw edema, in all periods evaluated, when compared to vehicle-treated groups $(p<0.001)$ (Figure 2). Maximum inhibition (98.87\%) was observed for 2 hours of treatment with MfAE at $100 \mathrm{mg} / \mathrm{kg}$. For the dose of $50 \mathrm{mg} / \mathrm{kg}$, the higher effect $(93.75 \%)$ was observed after 5 hours. The reference drug indomethacin $(20 \mathrm{mg} / \mathrm{kg})$ exhibited maximum inhibition (96.22\%) after 3 hours of treatment.

Carrageenan-induced paw edema is an experimental model useful for the evaluation of new agents acting on acute inflammation [64-66]. This test is considered a biphasic 
TABLe 2: Phytochemical analysis of extracts from fruit peels of Myrciaria floribunda.

\begin{tabular}{|c|c|c|c|c|c|}
\hline \multirow{2}{*}{ Class of secondary metabolites } & \multicolumn{5}{|c|}{ Extracts from fruit peels of Myrciaria floribunda } \\
\hline & MfEeE & MfCE & MfAE & MfME & MfAqE \\
\hline Flavonoid & - & - & $+^{*}$ & $+^{*}$ & $+^{*}$ \\
\hline Phenylpropanoid & - & - & + & - & - \\
\hline Triterpene & + & + & $\operatorname{tr}$ & - & - \\
\hline Steroid & + & + & $\operatorname{tr}$ & - & - \\
\hline Saponin & - & - & + & - & - \\
\hline Monoterpene and sesquiterpene & + & + & - & - & - \\
\hline Alkaloid & - & - & - & - & - \\
\hline Coumarin & - & - & - & - & - \\
\hline Quinone & - & - & - & - & - \\
\hline Proanthocyanidin and leucoanthocyanidin & - & - & - & $+^{* *}$ & $+^{* *}$ \\
\hline Hydrolysable tannin & - & - & + & + & + \\
\hline
\end{tabular}

-: negative; +: positive. Note. ${ }^{*} 3^{\prime}, 4^{\prime}-\mathrm{OH}$ flavonoids (aglycones, mono-, di-, and triglycosides). ${ }^{* *}$ Polymeric proanthocyanidins.

TABLE 3: Concentration of total phenols, total flavonoids, and monomeric anthocyanins in different extracts obtained from fruit peels of $M$. floribunda.

\begin{tabular}{lccc}
\hline Samples & Total phenol content $(\mathrm{mg} \mathrm{GAE} / \mathrm{g})$ & Total flavonoid content $(\mathrm{mg} \mathrm{QE} / \mathrm{g})$ & Anthocyanin content $(\mathrm{mg}$ Cy-3-glcE/g) \\
\hline MfEeE & 7.54 & 16.62 & ND \\
MfCE & ND & 3.46 & ND \\
MfAE & 296.27 & 0.74 & 35.65 \\
MfME & 158.29 & ND & 4.34 \\
MfAqE & 62.28 & ND & 14.42 \\
\hline
\end{tabular}

$\mathrm{ND}=$ not detected

TABle 4: Antioxidant activity of the extracts obtained from fruit peels of Myrciaria floribunda.

\begin{tabular}{lcccc}
\hline Samples & $\mathrm{DPPH} \mathrm{IC}_{50}(\mu \mathrm{g} / \mathrm{mL})$ & $\mathrm{ABTS}^{+}(\mu \mathrm{M}$ TEAC/g$)$ & TAC $(\%)$ & ${\text { Superoxide } \mathrm{IC}_{50}(\mu \mathrm{g} / \mathrm{mL})}$ \\
\hline MfEeE & 854.94 & 597.89 & 109.45 & $>1000$ \\
MfCE & $>1000$ & 347.89 & 68.87 & $>1000$ \\
MfAE & 63.84 & 1630.11 & 107.43 & 260.27 \\
MfME & 343.12 & 660.11 & 102.82 & 446.31 \\
MfAqE & 350.41 & 793.44 & - & NT \\
Gallic acid & 3.46 & - & - & - \\
\hline
\end{tabular}

$\mathrm{IC}_{50}=$ concentration required to reduce $50 \%$ of the DPPH or superoxide radical. TEAC $=$ Trolox equivalent antioxidant capacity. NT $=$ not tested.

event; in the initial phase ( 1 to 3 hours), the release of inflammatory mediators such as histamine, serotonin, and bradykinin occurs, while in the late phase (3 hours to 4 hours), the synthesis of cyclooxygenase 2 (COX-2) isoform occurs, leading to prostaglandins and nitric oxide release $[67,68]$. MfAE reduced the edema during the five hours observed, suggesting that it acts in both phases of the acute inflammatory process. Further, extracts from other Myrciaria plants also exhibited anti-inflammatory action in this model $[64,65]$.

The results suggest that the effect of MfAE in the formation of edema may involve multiple points such as the inhibition of the synthesis and/or release of inflammatory mediators, via COX or different specific enzymatic mechanism. The richness of polyphenols (flavonoids, anthocyanins) in MfAE has contributed towards the anti-inflammatory activity [60]. However, complementary studies based on these inflammatory mediators and COX inhibition should be explored, as well as phytochemical isolation.

3.7. Antinociceptive Activity. The treatment with both doses of MfAE also significantly inhibited the number of contortions $(95.16 \%$ and $95.59 \%$, resp.), compared to vehicle (saline) $(p<0.001)$. There were no differences neither between the different concentrations, nor in relation to the indomethacin control (Figure 3). In this test, acetic acid induces nociception through a mechanism that depends on the resident cells (macrophages and mast cells) presented at the peritoneal cavity. These cells release cytokines (TNF- $\alpha$, interleukin $1 \beta$, and interleukin 8 ) that are involved in the contortion response [69]. However, this model cannot infer whether the antinociceptive action of MfAE is central or peripheral. 


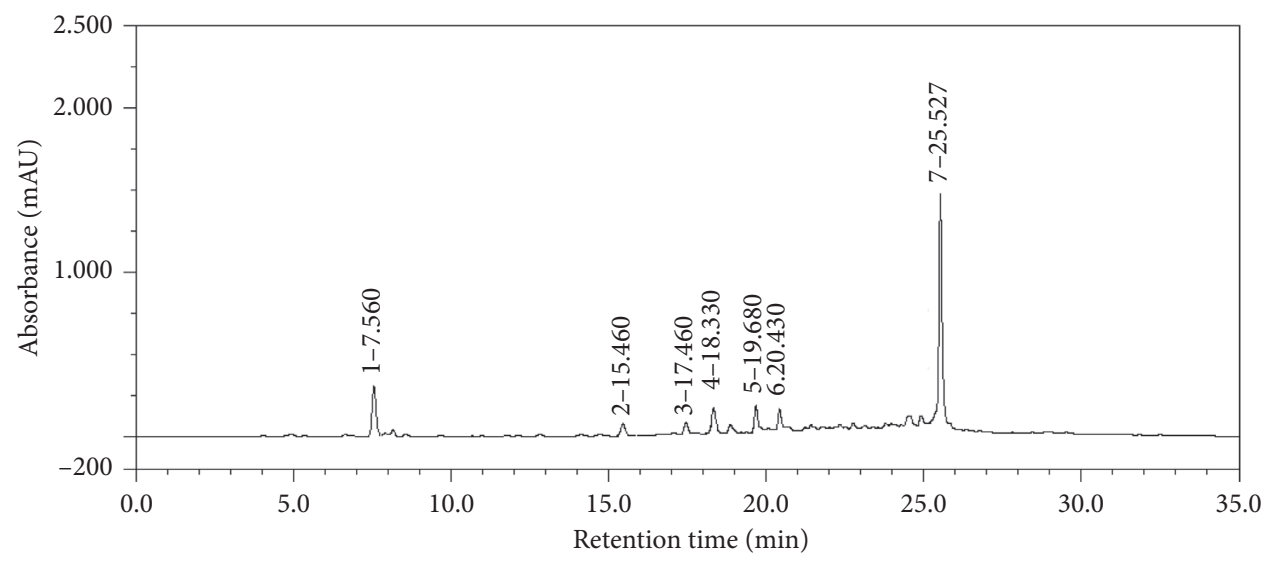

FIGURE 1: Chromatographic profile of the phenolic acids from acetone extract (MfAE). The extract was analyzed by HLPC at $270 \mathrm{~nm}$. Detected compounds: (1) gallic acid, (2)-(6) gallic acid derivatives, and (7) ellagic acid.

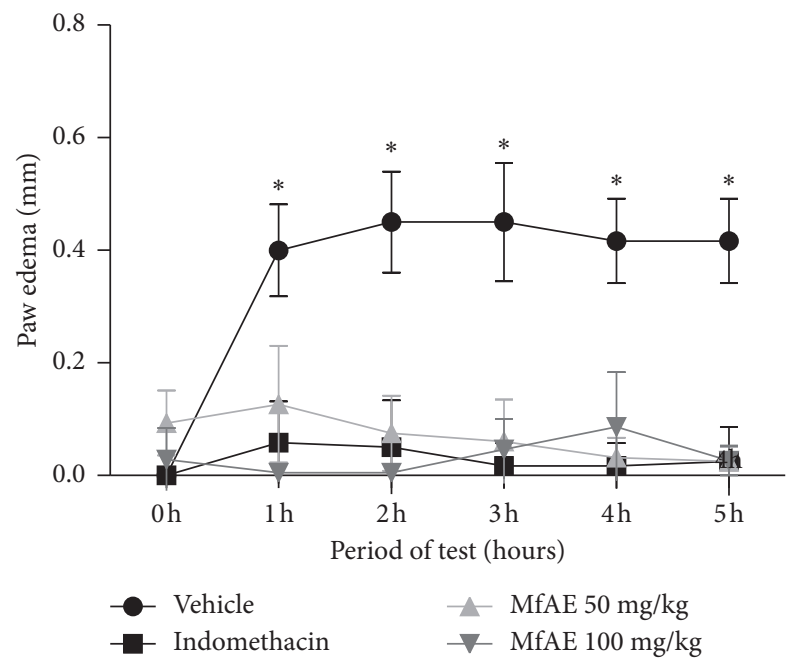

Figure 2: Effect of the acetone extract from fruit peels of Myrciaria floribunda (MfAE, 50 and $100 \mathrm{mg} / \mathrm{kg}$, v.o.) on carrageenan-induced paw edema. Each point represents the mean \pm SEM of the six animals. Asterisks indicate significance compared with vehicle group. ${ }^{*} p<0.001$, two-way ANOVA.

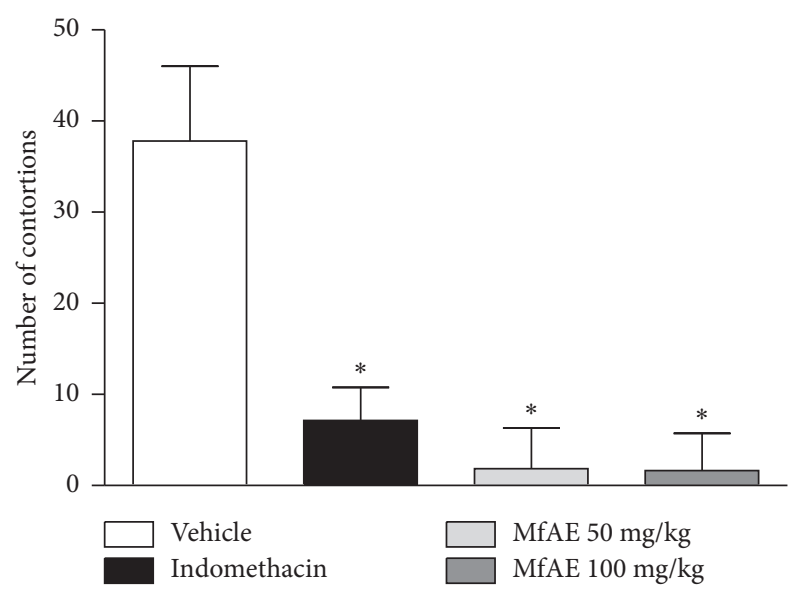

FIGURE 3: Effect of the acetone extract of the fruit peels of Myrciaria floribunda (MfAE, 50 and $100 \mathrm{mg} / \mathrm{kg}$, v.o.) on the abdominal contortion induced by acetic acid. Each column represents the mean \pm SEM of the number of contortions of the six animals. Asterisks indicate significance compared with vehicle group. ${ }^{*} p<0.001$, one-way ANOVA. 


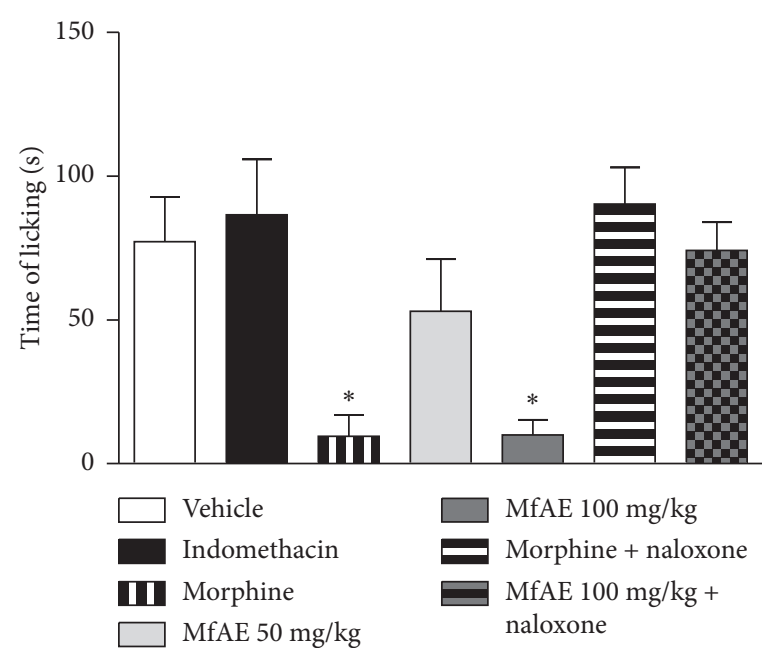

(a)

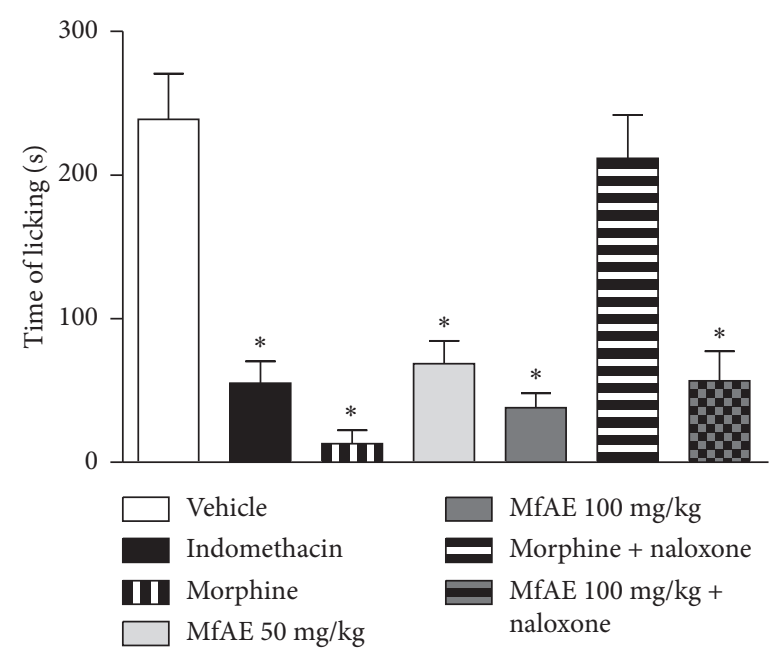

(b)

Figure 4: Effect of the acetone extract of the fruit peels of Myrciaria floribunda (MfAE, 50 and $100 \mathrm{mg} / \mathrm{kg}$, v.o.) on the formalin test. Stage 1: 0 to 5 minutes of test, neurogenic phase; Stage 2: 15 to 30 minutes of test, inflammatory phase. Each column represents the mean \pm SEM of the six animals. Asterisks indicate significance compared to the vehicle group. ${ }^{*} p<0.001$, one-way ANOVA.

Regarding the formalin test, the results shown in Figure 4 reveal that in the first phase (neurogenic phase) of the test, only the concentration of $100 \mathrm{mg} / \mathrm{kg}$ showed a significant reduction of licking $(86.52 \% ; p<0.001)$. Morphine $(10 \mathrm{mg} / \mathrm{kg})$ induced a reduction of $83.98 \%$ at this stage. However, in the second phase (inflammatory phase), both concentrations of MfAE had a significant reduction in licking time $(p<0.001)$. The inhibition was $69.47 \%$ and $82.58 \%$ for MfAE at $50 \mathrm{mg} / \mathrm{kg}$ and $100 \mathrm{mg} / \mathrm{kg}$, respectively. Positive controls, indomethacin $(20 \mathrm{mg} / \mathrm{kg})$ and morphine $(10 \mathrm{mg} / \mathrm{kg})$, inhibited $76.45 \%$ and $94.91 \%$ of licking, respectively. Naloxone reverted the effects of MfAE only in the neurogenic phase.

The formalin test is a nociception model based on a biphasic pain response; it is a useful tool to investigate whether the action of new agents has an analgesic and antiinflammatory effect [70]. In the first phase (neurogenic pain) which occurs up to 5 minutes after the injection of formalin in the paw, the direct chemical stimulation on nociceptors activates the afferent fibers and leads to the release of substance $\mathrm{P}$. In the inflammatory phase (15 to 30 minutes after the injection), the release of inflammatory mediators occurs, triggering a peripheral inflammatory response $[53,71]$.

Centrally acting analgesic drugs (such as morphine) are able to inhibit both phases of the formalin test; in contrast, peripherally acting drugs (such as indomethacin) inhibit only the second phase [72]. Our results demonstrate that MfAE at the dose of $100 \mathrm{mg} / \mathrm{kg}$ can reduce both phases of the nociceptive response $(p<0.001)$. In the first phase, the analgesic effect of MfAE $(100 \mathrm{mg} / \mathrm{kg})$ was mediated by the action on the opioid receptors, as naloxone reversed the effect of MfAE. This observation is attributed to the opioidergic mechanism that has been antagonized in the administration of naloxone (selective opioid receptor antagonist).

\section{Conclusion}

The results of this work show that the extracts from the peels of $M$. floribunda fruits are sources of compounds with antioxidant activity. The use of fruit peels, a possible residue of fruit consumption, represents a sustainable application of these natural products. In addition, the comparative analysis of antioxidant and phytochemical profiles allowed the selection of MfAE (a fraction rich in phenolic compounds and anthocyanins) as an agent high in pharmacological potential. MfAE also showed significant anti-inflammatory and antinociceptive activities (effect involving the opioidergic system). Considering the present results, the fruit peels of $M$. floribunda are sources of high-value bioactive compounds that may contribute to several beneficial effects associated with the consumption of this fruit. In this sense, the fruit peels can be used for development of functional foods and nutraceuticals.

\section{Data Availability}

The data that support the findings of this study are available from the corresponding author upon reasonable request.

\section{Conflicts of Interest}

The authors declare that there are no conflicts of interest regarding the publication of this paper.

\section{Authors' Contributions}

IBSS, AGS, MTSC, and MVS conceived the study and performed the study design. IBSS, JRSO, AGS, WKC, and MVS collected the plant material and performed the botanical identification and extracts preparation. IBSS, BSS, JRSO, and WKC performed the in vivo and in vitro assays. MRAF, RMX, and LALS performed the chemical 
characterization of the extracts. IBSS, BSS, AZ, LCNS, PMGP, VLML, MTSC, MVS, MRAF, RMX, and LALS interpreted and discussed the results. IBSS, BSS, AZ, LCNS, and MVS drafted and revised the manuscript. All authors approved the final version of this manuscript.

\section{Acknowledgments}

The authors acknowledge the technical support given by the Laboratory of Natural Products and the Laboratory of Molecular Biology, Department of Biochemistry of the Federal University of Pernambuco (UFPE). This work was supported by the following Brazilian agencies: Coordenação de Aperfeiçoamento de Pessoal de Nível Superior (CAPES; Finance Code 001), Conselho Nacional de Desenvolvimento Científico e Tecnológico (CNPq) (Grants nos. 405297/20181 and 307110/2018-4), Fundação de Amparo à Ciência e Tecnologia do Estado de Pernambuco (FACEPE) (APQ0493-4.03/14), and Fundação de Amparo à Pesquisa e ao Desenvolvimento Científico e Tecnológico do Maranhão (BEPP-02241/18).

\section{References}

[1] P. D. Ray, B. W. Huang, and Y. Tsuji, "Reactive oxygen species (ROS) homeostasis and redox regulation in cellular signaling," Cell Signal, vol. 24, no. 5, pp. 981-990, 2012.

[2] M. Schieber and N. S. Chandel, "ROS function in redox signaling and oxidative stress," Current Biology, vol. 24, no. 10, pp. R453-R462, 2014.

[3] V. Papayannopoulos, "Neutrophil extracellular traps in immunity and disease," Nature Reviews Immunology, vol. 18, no. 2, pp. 134-147, 2018.

[4] R. Radi, "Oxygen radicals, nitric oxide, and peroxynitrite: redox pathways in molecular medicine," Proceedings of the National Academy of Sciences, vol. 115, no. 23, pp. 5839-5848, 2018.

[5] J. P. Kehrer and L. O. Klotz, "Free radicals and related reactive species as mediators of tissue injury and disease: implications for Health," Critical Reviews in Toxicology, vol. 45, no. 9, pp. 765-798, 2015.

[6] L. C. Nascimento da Silva, C. M. Bezerra Filho, R. A. Paula et al., "In vitro cell-based assays for evaluation of antioxidant potential of plant-derived products," Free Radical Research, vol. 50, no. 8, pp. 801-812, 2016.

[7] C. Pena-Bautista, M. Baquero, M. Vento, and C. ChaferPericas, "Free radicals in Alzheimer's disease: lipid peroxidation biomarkers," Clinica Chimica Acta, vol. 491, pp. 8590, 2019.

[8] A. U. Ihsan, F. U. Khan, P. Khongorzul et al., "Role of oxidative stress in pathology of chronic prostatitis/chronic pelvic pain syndrome and male infertility and antioxidants function in ameliorating oxidative stress," Biomedicine \& Pharmacotherapy, vol. 106, pp. 714-723, 2018.

[9] I. Hossen, W. Hua, L. Ting et al., "Phytochemicals and inflammatory bowel disease: a review," Critical Reviews in Food Science and Nutrition, vol. 60, no. 8, pp. 1321-1345, 2020.

[10] H. J. Forman, "Redox signaling: an evolution from free radicals to aging," Free Radical Biology and Medicine, vol. 97, pp. 398-407, 2016.

[11] L. Chen, H. Deng, H. Cui et al., "Inflammatory responses and inflammation-associated diseases in organs," Oncotarget, vol. 9, no. 6, pp. 7204-7218, 2018.
[12] S. C. Gupta, A. B. Kunnumakkara, S. Aggarwal, and B. B. Aggarwal, "Inflammation, a double-edge sword for cancer and other age-related diseases," Frontiers in Immunology, vol. 9, p. 2160, 2018.

[13] L. A. Abdulkhaleq, M. A. Assi, R. Abdullah, M. Zamri-Saad, Y. H. Taufiq-Yap, and M. N. M. Hezmee, "The crucial roles of inflammatory mediators in inflammation: a review," Veterinary World, vol. 11, no. 5, pp. 627-635, 2018.

[14] J. Liu and X. Cao, "Cellular and molecular regulation of innate inflammatory responses," Cellular \& Molecular Immunology, vol. 13, no. 6, pp. 711-721, 2016.

[15] V. Chiurchiu, A. Leuti, and M. Maccarrone, "Bioactive lipids and chronic inflammation: managing the fire within," Frontiers in Immunology, vol. 9, p. 38, 2018.

[16] F. Sekiguchi, M. Tsubota, and A. Kawabata, "Involvement of voltage-gated calcium channels in inflammation and inflammatory pain," Biological and Pharmaceutical Bulletin, vol. 41, no. 8, pp. 1127-1134, 2018.

[17] R. R. Ji, A. Chamessian, and Y. Q. Zhang, "Pain regulation by non-neuronal cells and inflammation," Science, vol. 354, no. 6312, pp. 572-577, 2016.

[18] Y. Q. Zhou, Z. Liu, Z. H. Liu et al., "Interleukin-6: an emerging regulator of pathological pain," Journal of Neuroinflammation, vol. 13, no. 1, p. 141, 2016.

[19] F. A. Pinho-Ribeiro, W. A. Verri Jr., and I. M. Chiu, "Nociceptor sensory neuron-immune interactions in pain and inflammation," Trends in Immunology, vol. 38, no. 1, pp. 5-19, 2017.

[20] A. D. Cook, A. D. Christensen, D. Tewari, S. B. McMahon, and J. A. Hamilton, "Immune cytokines and their receptors in inflammatory pain," Trends Immunol, vol. 39, no. 3, pp. 240-255, 2018.

[21] S. K. Totsch and R. E. Sorge, "Immune system involvement in specific pain conditions," Molecular Pain, vol. 13, 2017.

[22] I. Obara, V. Telezhkin, I. Alrashdi, and P. L. Chazot, "Histamine, histamine receptors, and neuropathic pain relief," British Journal of Pharmacology, vol. 177, no. 3, pp. 580-599, 2020.

[23] M. Matsuda, Y. Huh, and R. R. Ji, "Roles of inflammation, neurogenic inflammation, and neuroinflammation in pain," Journal of Anesthesia, vol. 33, no. 1, pp. 131-139, 2019.

[24] L. P. Sousa, A. L. Alessandri, V. Pinho, and M. M. Teixeira, "Pharmacological strategies to resolve acute inflammation," Current Opinion in Pharmacology, vol. 13, no. 4, pp. 625-631, 2013.

[25] M. Perretti, X. Leroy, E. J. Bland, and T. Montero-Melendez, "Resolution pharmacology: opportunities for therapeutic innovation in inflammation," Trends in Pharmacological Sciences, vol. 36, no. 11, pp. 737-755, 2015.

[26] H. Chahdoura, S. El Bok, T. Refifa et al., "Activity of antiinflammatory, analgesic and antigenotoxic of the aqueous flower extracts of Opuntia microdasys Lem.Pfeiff," Journal of Pharmacy and Pharmacology, vol. 69, no. 8, pp. 1056-1063, 2017.

[27] O. G. Quinones, B. H. Hossy, T. A. Padua et al., "Copaiba oil enhances in vitro/in vivo cutaneous permeability and in vivo anti-inflammatory effect of celecoxib," Journal of Pharmacy and Pharmacology, vol. 70, no. 7, pp. 964-975, 2018.

[28] A. Kumar, S. Singh, A. Kumar et al., "Chemical composition, bactericidal kinetics, mechanism of action, and anti-inflammatory activity of Isodon melissoides (Benth.) H. Hara essential oil," Natural Product Research, pp. 1-6, 2016.

[29] D. W. Lim, J. G. Kim, and Y. T. Kim, "Analgesic effect of Indian gooseberry (emblica officinalis fruit) extracts on 
postoperative and neuropathic pain in rats," Nutrients, vol. 8 , no. 12, 2016.

[30] M. Serafini and I. Peluso, "Functional foods for health: the interrelated antioxidant and anti-inflammatory role of fruits, vegetables, herbs, spices and cocoa in humans," Current Pharmaceutical Design, vol. 22, no. 44, pp. 6701-6715, 2017.

[31] A. Basu, J. Schell, and R. H. Scofield, "Dietary fruits and arthritis," Food \& Function, vol. 9, no. 1, pp. 70-77, 2018.

[32] M. Gasparrini, F. Giampieri, T. Y. Forbes-Hernandez et al., "Strawberry extracts efficiently counteract inflammatory stress induced by the endotoxin lipopolysaccharide in Human Dermal Fibroblast," Food and Chemical Toxicology, vol. 114, pp. 128-140, 2018.

[33] I. Peluso, D. Villano Valencia, C. O. Chen, and M. Palmery, "Antioxidant, anti-inflammatory, and microbial-modulating activities of nutraceuticals and functional foods," Oxidative Medicine and Cellular Longevity, vol. 2018, Article ID 3824509, 2018.

[34] N. R. F. Leal, M. V. Vigliano, F. A. Pinto et al., "Anti-inflammatory effect of diterpenes-enriched fractions from Pterodon polygalaeflorus through inhibition of macrophage migration and cytokine production," Journal of Pharmacy and Pharmacology, vol. 70, no. 6, pp. 808-820, 2018.

[35] L. M. de Oliveira, A. Porte, R. L. de Oliveira Godoy et al., "Chemical characterization of Myrciaria floribunda (H. West ex Willd) fruit," Food Chemistry, vol. 248, pp. 247-252, 2018.

[36] M. M. L. de Azevedo, M. M. Cascaes, G. Guilhon et al., "Lupane triterpenoids, antioxidant potential and antimicrobial activity of Myrciaria floribunda (H. West ex Willd.) O. Berg," Natural Product Research, vol. 33, no. 4, pp. 1-10, 2019.

[37] L. A. C. Tietbohl, A. P. Oliveira, R. S. Esteves et al., "Antiproliferative activity in tumor cell lines, antioxidant capacity and total phenolic, flavonoid and tannin contents of Myrciaria floribunda," Anais da Academia Brasileira de Ciências, vol. 89, no. 2, pp. 1111-1120, 2017.

[38] T. Brassuer and L. Angenot, "Le mélange diphénylborate d'aminoéthanol-PEG 400: un intéressant réactif de révélation des flavonoïdes," Journal of Chromatography A, vol. 351, pp. 351-355, 1986.

[39] P. M. Richardson, "Phytochemical methods: a guide to modern techniques of plant analysis," Brittonia, vol. 42, no. 2, p. 115, 1990.

[40] E. Roberts, R. Cartwright, and M. Oldschool, "The phenolic substances of manufactured tea. I.-fractionation and paper chromatography of water-soluble substances," Journal of the Science of Food and Agriculture, vol. 8, no. 2, pp. 72-80, 1957.

[41] H. Wagner and S. Bladt, "Flavonoid drugs including ginkgo biloba and echinaceae species," in Plant Drug Analysis: A Thin Layer Chromatography Atlas, pp. 195-245, Springer, Berlin, Germany, 1996.

[42] V. L. Singleton and J. A. Rossi, "Colorimetry of total phenolics with phosphomolybdic-phosphotungstic acid reagents," American Journal of Enology and Viticulture, vol. 16, no. 3, pp. 144-158, 1965.

[43] R. G. Woisky and A. Salatino, "Analysis of propolis: some parameters and procedures for chemical quality control," Journal of Apicultural Research, vol. 37, no. 2, pp. 99-105, 1998.

[44] F. S. Hosseinian, W. Li, and T. Beta, "Measurement of anthocyanins and other phytochemicals in purple wheat," Food Chemistry, vol. 109, no. 4, pp. 916-924, 2008.

[45] W. Brand-Williams, M.-E. Cuvelier, and C. Berset, "Use of a free radical method to evaluate antioxidant activity," LWTfood Science and Technology, vol. 28, no. 1, pp. 25-30, 1995.
[46] R. Re, N. Pellegrini, A. Proteggente, A. Pannala, M. Yang, and C. Rice-Evans, "Antioxidant activity applying an improved ABTS radical cation decolorization assay," Free Radical Biology and Medicine, vol. 26, no. 9-10, pp. 1231-1237, 1999.

[47] P. Prieto, M. Pineda, and M. Aguilar, "Spectrophotometric quantitation of antioxidant capacity through the formation of a phosphomolybdenum complex: specific application to the determination of vitamin E," Analytical Biochemistry, vol. 269, no. 2, pp. 337-341, 1999.

[48] E. Kunchandy and M. Rao, "Oxygen radical scavenging activity of curcumin," International Journal of Pharmaceutics, vol. 58, no. 3, pp. 237-240, 1990.

[49] D. Lorke, "A new approach to practical acute toxicity testing," Archives of Toxicology, vol. 54, no. 4, pp. 275-287, 1983.

[50] C. A. Winter, E. A. Risley, and G. W. Nuss, "Carrageenininduced edema in hind paw of the rat as an assay for antiinflammatory drugs," Proceedings of the Society for Experimental Biology and Medicine, vol. 111, no. 3, pp. 544-547, 1962.

[51] G.-J. Huang, C.-H. Pan, F.-C. Liu, T.-S. Wu, and C.-H. Wu, "Anti-inflammatory effects of ethanolic extract of Antrodia salmonea in the lipopolysaccharide-stimulated RAW246. 7 macrophages and the $\lambda$-carrageenan-induced paw edema model," Food and Chemical Toxicology, vol. 50, no. 5, pp. 1485-1493, 2012.

[52] H. Collier, L. Dinneen, C. A. Johnson, and C. Schneider, "The abdominal constriction response and its suppression by analgesic drugs in the mouse," British Journal of Pharmacology and Chemotherapy, vol. 32, no. 2, pp. 295-310, 1968.

[53] S. Hunskaar and K. Hole, "The formalin test in mice: dissociation between inflammatory and non-inflammatory pain," Pain, vol. 30, no. 1, pp. 103-114, 1987.

[54] M. Plaza, A. G. Batista, C. B. Cazarin et al., "Characterization of antioxidant polyphenols from Myrciaria jaboticaba peel and their effects on glucose metabolism and antioxidant status: a pilot clinical study," Food Chemistry, vol. 211, pp. 185-197, 2016.

[55] S. C. M. Burri, A. Ekholm, A. Hakansson, E. Tornberg, and K. Rumpunen, "Antioxidant capacity and major phenol compounds of horticultural plant materials not usually used," Journal of Functional Foods, vol. 38, pp. 119-127, 2017.

[56] B. W. Lin, C. C. Gong, H. F. Song, and Y. Y. Cui, "Effects of anthocyanins on the prevention and treatment of cancer," British Journal of Pharmacology, vol. 174, no. 11, pp. 12261243, 2017.

[57] Y. Zhang, T. Pechan, and S. K. C. Chang, "Antioxidant and angiotensin-I converting enzyme inhibitory activities of phenolic extracts and fractions derived from three phenolicrich legume varieties," Journal of Functional Foods, vol. 42, pp. 289-297, 2018.

[58] F. Altieri, F. Cairone, F. Giamogante et al., "Influence of ellagitannins extracted by pomegranate fruit on disulfide isomerase PDIA3 activity," Nutrients, vol. 11, no. 1, p. 186, 2019.

[59] D. Fracassetti, C. Costa, L. Moulay, and F. A. Tomas-Barberan, "Ellagic acid derivatives, ellagitannins, proanthocyanidins and other phenolics, vitamin $\mathrm{C}$ and antioxidant capacity of two powder products from camu-camu fruit (Myrciaria dubia)," Food Chemistry, vol. 139, no. 1-4, pp. 578-588, 2013.

[60] D. K. Zhao, Y. N. Shi, V. Petrova et al., "Jaboticabin and related polyphenols from jaboticaba (Myrciaria cauliflora) with anti-inflammatory activity for chronic obstructive 
pulmonary disease," Journal of Agricultural and Food Chemistry, vol. 67, no. 5, pp. 1513-1520, 2019.

[61] M. Daglia, A. Di Lorenzo, S. F. Nabavi, Z. S. Talas, and S. M. Nabavi, "Polyphenols: well beyond the antioxidant capacity: gallic acid and related compounds as neuroprotective agents: you are what you eat!" Current Pharmaceutical Biotechnology, vol. 15, no. 4, pp. 362-372, 2015.

[62] L. A. BenSaad, K. H. Kim, C. C. Quah, W. R. Kim, and M. Shahimi, "Anti-inflammatory potential of ellagic acid, gallic acid and punicalagin $\mathrm{A} \& \mathrm{~B}$ isolated from Punica granatum," BMC Complementary and Alternative Medicine, vol. 17, no. 1, p. 47, 2017.

[63] OCDE, Acute Oral Toxicity: Up and Down Procedure OECD Guideline for the Testing of Chemicals, vol. 425, pp. 1-2, OCDE, Paris, France, 2008.

[64] M. A. Apel, M. E. Lima, M. Sobral et al., "Anti-inflammatory activity of essential oil from leaves of Myrciaria tenella and Calycorectes sellowianus," Pharmaceutical Biology, vol. 48, no. 4, pp. 433-438, 2010.

[65] K. Yazawa, K. Suga, A. Honma, M. Shirosaki, and T. Koyama, "Anti-inflammatory effects of seeds of the tropical fruit camucamu (Myrciaria dubia)," Journal of Nutritional Science and Vitaminology, vol. 57, no. 1, pp. 104-107, 2011.

[66] S. K. Dev, P. K. Choudhury, R. Srivastava, and M. Sharma, "Antimicrobial, anti-inflammatory and wound healing activity of polyherbal formulation," Biomedicine \& Pharmacotherapy, vol. 111, pp. 555-567, 2019.

[67] A. N. Daniel, S. M. Sartoretto, G. Schmidt, S. M. CaparrozAssef, C. A. Bersani-Amado, and R. K. N. Cuman, "Antiinflammatory and antinociceptive activities A of eugenol essential oil in experimental animal models," Revista Brasileira de Farmacognosia, vol. 19, no. 1, pp. 212-217, 2009.

[68] L. C. Ferreira, A. Grabe-Guimarães, C. A. de Paula et al., "Anti-inflammatory and antinociceptive activities of Campomanesia adamantium," Journal of Ethnopharmacology, vol. 145, no. 1, pp. 100-108, 2013.

[69] R. A. Ribeiro, M. L. Vale, S. M. Thomazzi et al., "Involvement of resident macrophages and mast cells in the writhing nociceptive response induced by zymosan and acetic acid in mice," European Journal of Pharmacology, vol. 387, no. 1, pp. 111-118, 2000.

[70] R. T. Basting, C. M. Nishijima, J. A. Lopes et al., “Antinociceptive, anti-inflammatory and gastroprotective effects of a hydroalcoholic extract from the leaves of Eugenia punicifolia (Kunth) DC. in rodents," Journal of Ethnopharmacology, vol. 157, pp. 257-267, 2014.

[71] A. Tjølsen, O.-G. Berge, S. Hunskaar, J. H. Rosland, and K. Hole, "The formalin test: an evaluation of the method," Pain, vol. 51, no. 1, pp. 5-17, 1992.

[72] D. Z. Viscardi, J. da Silva Arrigo, C. d. A. C. Correia et al., "Seed and peel essential oils obtained from Campomanesia adamantium fruit inhibit inflammatory and pain parameters in rodents," PLoS One, vol. 12, no. 2, Article ID e157107, 2017. 